\title{
Synthesis and Characterization of Zinc Carboxylates as Aqueous Corrosion Inhibitors for Mild Steel and 2024, 6061, and 7075 Aluminum Alloys
}

\author{
Volkan Cicek $^{1}$, Mehmet Ozdemir ${ }^{1}$, Allen W. Apblett ${ }^{2}$ \\ ${ }^{1}$ Faculty of Science \& Engineering, Ishik University, Erbil, Iraq \\ ${ }^{2}$ Department of Chemistry, Oklahoma State University, Stillwater, OK 74078, USA \\ Correspondence: Volkan Cicek, Faculty of Science \& Engineering, 100 meter street, Ishik University, Erbil, Iraq. \\ Tel: 964-750-317-9477. E-mail: volkancicek@gmail.com; volkan.cicek@ishikuniversity.net
}

\author{
Received: November 14, 2012 Accepted: January 19, 2013 Online Published: April 7, 2013 \\ doi:10.5539/ijc.v5n2p7 \\ URL: http://dx.doi.org/10.5539/ijc.v5n2p7
}

\begin{abstract}
Synthesis and characterization of environmentally friendly metallo-organic corrosion inhibitors for protection of mild steel and certain aluminum alloys are being sought to replace carcinogenic hexavalent chromium based corrosion inhibitors. Given the toxicity and carcinogenicity of chromates, the purpose of this study is not just synthesizing any efficient corrosion inhibitors for certain alloys of certain metals to be applied in different environments, but also to find environmentally friendly corrosion inhibitors for successful chromate replacements. In this regard, the standard for an environmentally friendly inhibitor is considered as having acceptable or no toxicity compared to chromate inhibitors. Studying the reasons underlying the success of chromate inhibitors seems to be the first reasonable approach one might take before formulating chromate replacements. Therefore, synergistic combinations of carboxylic acids and zinc cation, which is well-known for its cationic inhibiting efficiency producing carboxylate salts of zinc with a general formula of ( $\mathrm{Zn}$ ) (hydroxyacid $)_{2}$ are aimed to be synthesized and characterized. Practical results have proven the hypothesized advantages of zinc carboxylates correct and yielded that certain zinc carboxylates can be suitable corrosion inhibitors for certain metals and their alloys under specific circumstances.
\end{abstract}

Keywords: synergistic, carcinogenic, toxic, inhibiting efficiency

\section{Introduction}

In this investigation, synthesis and characterization of environmentally friendly metallo-organic corrosion inhibitors for protection of mild steel and certain aluminum alloys are being sought to replace carcinogenic hexavalent chromium based corrosion inhibitors. Hexavalent $\mathrm{Cr}^{6+}$ within biological systems is highly toxic, carcinogenic and a very hazardous soil and groundwater pollutant also having adverse toxicity to aquatic life. Dermatitis, skin and lung cancers are amongst the diseases associated with hexavalent chromium in the literature.

For this reason, several corrosion inhibiting species were combined in a single compound and were tested alongside the individual components that are known for their corrosion inhibiting efficiencies in order to determine whether there were any synergistic interactions. Cationic constituent that is zinc cation in this study is known for its cationic inhibiting efficiency; while the other constituent that is either gallic, mandelic or tartaric acid throughout the study are hydroxy acids, which are, as a group of compounds, also known for their inhibiting efficiencies in aqueous solutions. However, despite gallic, mandelic and tartaric acid belong to the group of hydroxy acids, which as a group of compounds known for their inhibiting efficiencies in aqueous solutions, there is insufficient research data with regards to the synthesis and use of their synergistic formulations for the purpose of being used as corrosion inhibitors, least as replacements of carcinogenic hexavalent chromium compounds.

Zinc gluconate or zinc (2R,3S,4R,5R)-2,3,4,5,6-pentahydroxyhexanoate constitutes a known example of such corrosion inhibitors that has inspired this research to take place. Zinc gluconate is a popular form for the delivery of zinc as a dietary supplement and is widely used in the field of medicinal health as a nutritional supplement opposed to the carcinogenic hexavalent chromium compounds, which are used as commercial inhibitors. Zinc gluconate is found naturally, while industrially it is manufactured via fermentation of glucose. In its pure form, it 
is a white to off-white powder. It can also be manufactured by electrolytic oxidation, which yields a lower microbiological profile with longer shelf life, although it is a more expensive process (de Wilt, 2006). Zinc(II) aqua complex reacts with gluconate ion to form monovalent zinc gluconate complex, which leads to the formation of divalent zinc gluconate complex.

$$
\begin{aligned}
& {\left[\mathrm{Zn}\left(\mathrm{OH}_{2}\right)_{6}\right]^{2+}+\mathrm{HO}-\mathrm{CH}_{2}-(\mathrm{CH}-\mathrm{OH})_{4}-\mathrm{CO} \longleftrightarrow\left\{\mathrm{Zn}\left[\mathrm{HO}-\mathrm{CH}_{2}-(\mathrm{CH}-\mathrm{OH})_{4}-\mathrm{COO}^{-}\right]\right\}^{+1}} \\
& \left\{\mathrm{Zn}\left[\mathrm{HO}-\mathrm{CH}_{2}-(\mathrm{CH}-\mathrm{OH})_{4}-\mathrm{COO}^{-}\right]\right\}^{+1}+\mathrm{HO}_{-} \mathrm{CH}_{2}-(\mathrm{CH}-\mathrm{OH})_{4}-\mathrm{COO}^{-} \longrightarrow \mathrm{Zn}\left[\mathrm{HO}-\mathrm{CH}_{2}-(\mathrm{CH}-\mathrm{OH})_{4}-\mathrm{COO}^{-}\right]_{2}
\end{aligned}
$$

Formation constant of divalent zinc gluconate is 1.70 indicating a relatively low-strength complex (Furia, 2006). Zinc cation mostly forms octahedral complexes, however its tetrahedral complexes are also known. A tetrahedral structure might be favored in aqueous solutions due to charge neutrality and the size difference between the zinc cation with that of gluconate anion as pointed out in the literature (Graves et al., 2005).

\section{Materials and Methods of Synthesis}

All reagents used for synthesis were ACS reagent grade or higher and used without further purification. Some of these species were commercially available resulting in their direct use with no synthesis required. Among readily available compounds solely used as precursor were carboxylic acids with varying solubilities such as gallic acid, mandelic acid, tartaric acid, thus optimum "window of solubility" could be achieved as well as sodium hydroxide, ammonium hydroxide, potassium hydroxide and zinc nitrate. Window of solubility defines a range of solubility values, which are not too high thus the corrosion inhibitor are not leached away and also are not too low so the corrosion inhibitors can reach the locations where there is corrosion and contribute to the inhibition process.

The first step of the synthesis was the formation of the sodium or ammonium salt of the acid by reacting it with ammonium or sodium hydroxide. Small amounts of reactants, such as $20 \mathrm{mmol}$ equaling to one equivalance, were refluxed in $100 \mathrm{ml}$ up to several hundred $\mathrm{ml}$ of distilled water for a few hours up to a period of overnight, followed by the isolation of product mostly via rotary evaporation or by precipitation in methanol given the product is not soluble in methanol. The byproducts $\mathrm{NH}_{4} \mathrm{NO}_{3}$ and $\mathrm{NaNO}_{3}$ were washed away during filtration. In the second step, these hydroxy acid salts were reacted with zinc nitrate to form the desired product. Table 1 details the product and reagent information along with the required amounts of reactants in mmol and the quantities of solutions in mls, where additional information specific to certain products are also included.

\begin{tabular}{|c|c|c|c|c|}
\hline Product & Reagents & $\begin{array}{l}\text { Amount } \\
(\mathrm{mmols})\end{array}$ & $\begin{array}{l}\text { Water/soln. } \\
\quad(\mathrm{ml})\end{array}$ & $\begin{array}{l}\text { Additional } \\
\text { Information }\end{array}$ \\
\hline \multirow{2}{*}{ Ammonium Mandelate } & Ammonium Hydroxide & 20 & \multirow{2}{*}{100} & \\
\hline & Mandelic Acid & 20 & & \\
\hline \multirow{2}{*}{ Zinc Mandelate } & Zinc Nitrate & 15 & \multirow{2}{*}{150} & \multirow{2}{*}{$75 \% *$} \\
\hline & Ammonium Mandelate & 15 & & \\
\hline \multirow{2}{*}{ Sodium Tartrate } & Sodium Hydroxide & 20 & \multirow{2}{*}{100} & \\
\hline & Tartaric Acid & 20 & & \\
\hline \multirow{2}{*}{ Zinc Tartrate } & Zinc Nitrate & 40 & \multirow{2}{*}{150} & \\
\hline & Sodium Tartrate & 40 & & \\
\hline \multirow{2}{*}{ Ammonium Gallate } & Ammonium Hydroxide & 100 & \multirow{2}{*}{250} & \\
\hline & Gallic Acid & 100 & & \\
\hline \multirow{2}{*}{ Zinc Gallate } & Zinc Nitrate & 50 & \multirow{2}{*}{150} & \\
\hline & Ammonium Gallate & 50 & & \\
\hline
\end{tabular}

Table 1. Designated reagent/solvent amounts for synthesis reactions

$*_{\mathrm{w}} /$ respect to product formula of sodium mandelate. 
Additional Information:

- Unless stated all products were obtained via reflux.

- In addition to the mentioned amounts of reagents, very high amounts of reagents were also used in the same proportions to synthesize products in bulk amounts when needed in weight-loss and salt fog chamber tests.

\subsection{Zinc Tartrate}

As a result of the procedures described above, zinc tartrate was successfully synthesized from sodium tartrate and zinc nitrate similar to other zinc carboxylates attempted. In the case of zinc tartrate, its XRD pattern was isostructured to that of manganese tartrate as shown in Figure 1.

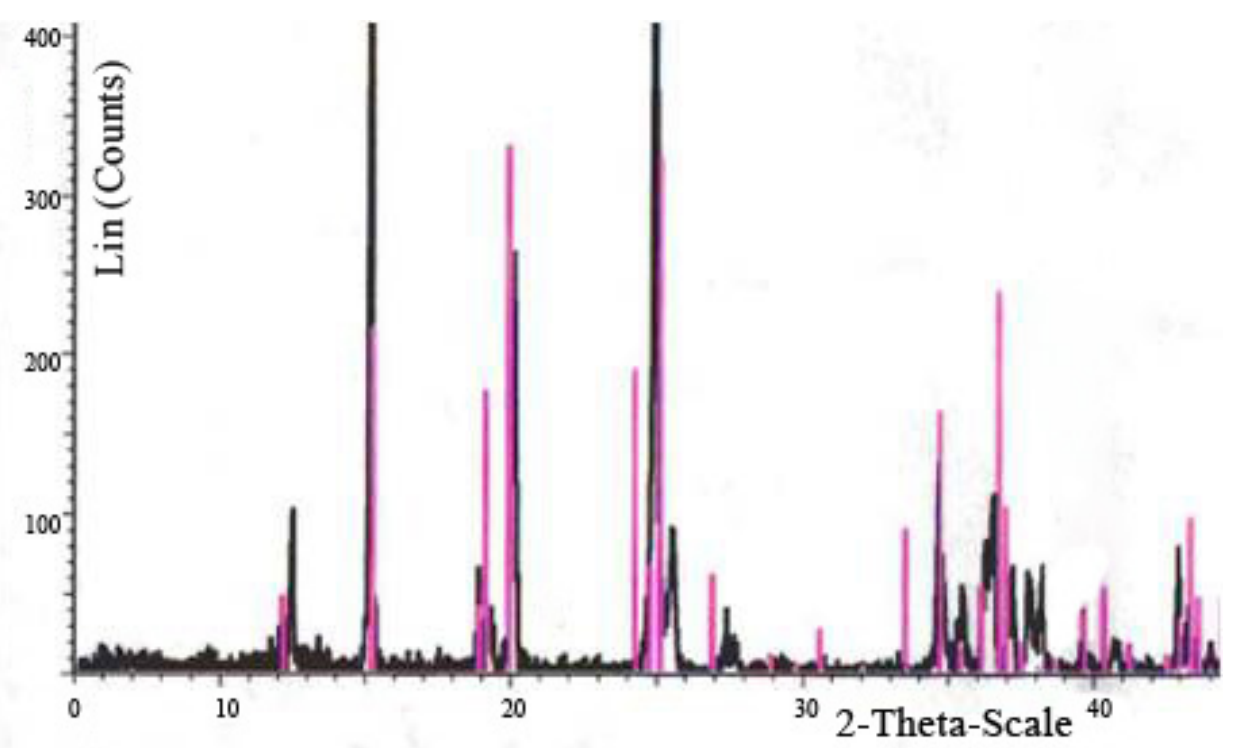

Figure 1. X-ray diffraction pattern of zinc tartrate

\subsection{Zinc Mandelate}

Zinc mandelate was synthesized via reaction of ammonium salt of mandelic acid with zinc nitrate.

\subsection{Zinc Gallate}

Like zinc mandelate, zinc gallate was synthesized from ammonium salt of gallic acid and zinc nitrate. Gallic acid has been chosen as a reactant since its structure mimics the chemicals that mussels use to adhere to both inorganic and organic surfaces. Among this group of chemicals of substituted phenols that mussels use is 3,4-dihydroxy-L-phenylalanine as shown in Figure 2.<smiles>N[C@@H](Cc1ccc(O)c(O)c1)C(=O)O</smiles>

Figure 2. Structure of 3,4-dihydroxy-L-phenylalanine 


\section{Characterization Studies of the Synthesized Compounds}

\subsection{FT-IR Spectroscopic Studies}

FT-IR spectroscopy has been used extensively for the characterization of the synthesized chemicals and substrate coupon surfaces immersed in inhibitor solutions. Infrared spectroscopy measurements were performed using a Nicolet Magna-IR 75 spectrometer. Spectra were collected in the $400-4000 \mathrm{~cm}^{-1}$ range using 128 scans and a resolution of $4 \mathrm{~cm}^{-1}$. The background was eliminated using spectra of degreased blank alloy coupon as a reference. For the infrared spectra of the synthesized compounds, $\mathrm{KBr}$ pellets are prepared carefully. The compositions of the $\mathrm{KBr}$ pellets were determined based on the predicted strength of the absorptions of functional groups present in the sample. FT-IR spectrum of zinc tartrate is shown in Figure 3.

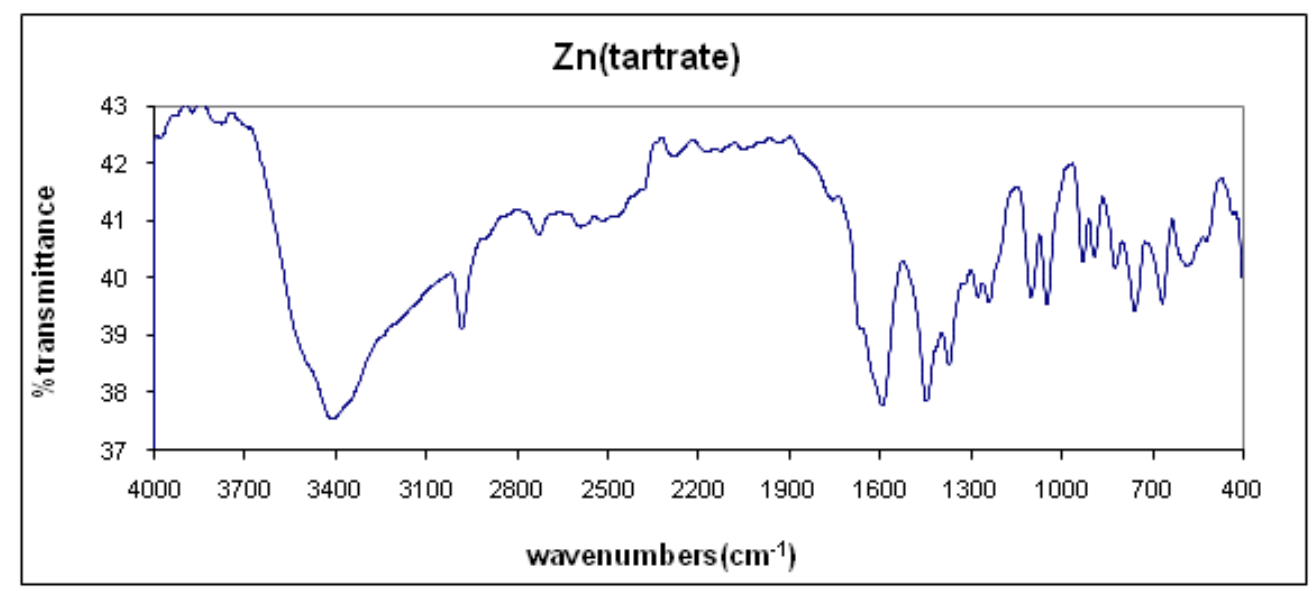

Figure 3. Infrared spectrum of zinc tartrate

The IR spectra of zinc tartrate and that of other zinc carboxylates were similar to the spectra of other hydroxy-acid salts in general with the distinction of broadening of $\mathrm{CH}_{2}, \mathrm{COH}$ and $\mathrm{CHO}$ bending vibrations and $\mathrm{OH}$ stretching vibrations due to metal hydroxy-acid interactions. All bands due to the tartrate constituent had one to one match with that of potassium tartrate measured by a Nicolet 20SX FT-IR as reported in the literature (Almond \& Hahne, 1988). The absorption at $840 \mathrm{~cm}^{-1}$ suggests the presence of tetrahedral coordination of $\mathrm{Zn}$ (Yawale et al., 2000). Absence of any bands at $420 \mathrm{~cm}^{-1}$ indicates the absence of $\mathrm{Zn}-\mathrm{O}$ bond (Sigoli et al., 1997).

\subsection{Powder X-Ray Diffraction Studies}

X-ray powder diffraction patterns were recorded on a Bruker AXS D-8 Advance X-ray powder diffractometer using copper $\mathrm{K}_{\alpha}$ radiation. X-ray diffractometer studies successfully revealed the structures of zinc tartrate as shown in Figure 1 and also of zinc mandelate, but not zinc gallate's, since it was amorphous.

\section{Results and Discussion}

A new group of novel metallo-organic compounds were synthesized and tested for use as chromate replacements in corrosion inhibition applications of mild steel and aluminum alloys. For this reason, certain anions and cations that are well-known for their corrosion inhibiting properties were combined under one formulation with the general formula of $(\mathrm{Zn})$ (hydroxyacid) $)_{\mathrm{x}}$. In the place of hydroxy-acid, tartaric, mandelic and gallic acids were used. Products were synthesized via a single-source precursor method, which is a relatively easier synthesis method. Characterization studies on the other hand were proven to be difficult due to amorphous structure of zinc gallate, which in turn resulted in no structural information through X-ray analysis.

Further studies must be conducted to put the synthesized zinc carboxylates' corrosion inhibition efficiencies into test. Authors of the study plan to test these potential inhibitors initially via weight-loss and salt-fog chamber methods, which are commonly performed under circumstances, where high salt concentrations were present. For weight-loss tests, high salt concentrations were applied for accelerated corrosion testing purposes in addition to simulating the actual highly corrosive environments such as marine environments, seawater, and industrial areas. In the case of salt-fog chamber tests, chemical stress in accelerated testing primarily refers to chloride containing salts in solution because airborne contaminants are believed to play a very minor role in paint aging (Forsgren, 2006). 


\section{Conclusion}

In this study, synthesis and characterization of environmentally friendly metallo-organic corrosion inhibitors for protection of mild steel and certain aluminum alloys are being sought to replace carcinogenic hexavalent chromium based corrosion inhibitors. Given the toxicity and carcinogenicity of chromates, the purpose of this study was not just synthesizing any efficient corrosion inhibitors for certain alloys of certain metals to be applied in different environments, but also to find environmentally friendly corrosion inhibitors for successful chromate replacements. In this regard, environmentally friendly zinc carboxylates are synthesized in this study. Zinc carboxylates that are synthesized and characterized in this study theoretically have the potential to act as synergistic inhibitors due to the well-established cathodic inhibiting efficiencies of zinc cations and the inhibiting efficiencies of hydroxy acids in aqueous solutions along with a more optimum window of solubility provided by gallate, mandelate or tartrate constituents compared to other successful hydroxy acid inhibitors available in the market such as gluconates. This hypothesis will be put into test by further studies using other techniques such as weight loss tests, salt-fog chamber tests, electrochemical spectroscopy, etc.

\section{Acknowledgements}

Assoc. Prof. Dr. Allen Apblett is acknowledged for the expertise and knowledge he provided me during my PhD education making it possible for me to proceed further in research and science. Also, Ishik University is acknowledged for the financial sponsorship provided.

\section{References}

Almond, M. J., \& Hahne, M. (1988). Formation Of Molecular Chromium(IV) Oxide $\left(\mathrm{CrO}_{2}\right)$ By Photolysis Of $\mathrm{Cr}(\mathrm{CO})_{6}$ in $\mathrm{O}_{2}$-Doped Argon Matrices. J. Chem. Soc. Dalton Trans., 2256.

De Wilt, H. G. J. (2006). Part I: The oxidation of Glucose to Gluconic Acid. Ind. Eng. Chem. Prod. Res. Develop., 11(4), 370. http://dx.doi.org/10.1201/9781420007022

Forsgren, A. (2006). Corrosion Control through Organic Coatings (pp. 115-121). Boca Raton, FL: CRC Press. http://dx.doi.org/10.1201/9781420007022

Furia, T. E. (2006). Sequestrants in Foods, Handbook of Food Additives (2nd ed., p. 271). CRC Press.

Graves, C. R., Campbell, E. J., \& Nguyen, S. T. (2005). Aluminum-based catalysts for the asymmetric Meerwein-Schmidt-Ponndorf-Verley-Oppenauer (MSPVO) reaction manifold. Tetrahedron: Asymmetry, 16(21), 3465. http://dx.doi.org/10.1016/j.tetasy.2005.08.058

Sigoli, F. A., Davolos, M. R., \& Jafelicci, Jr., M. (1997). Morphological Evolution of Zinc Oxide Originating from Zinc Hydroxide Carbonate. J. of Alloys and Compounds, 262-263, 293. http://dx.doi.org/10.1016/S0925-8388(97)00404-0

Yawale, S. S., Yawale, S. P., \& Adgaonkar, C. S. (2000). Infrared investigation of some borate glasses. Indian J. Engg. Mater. Sci., 7, 150. 